\title{
NOTAS SOBRE LA HISTORIOGRAFIA DEL PENSAMIENTO ECONOMICO EN ESPAÑA. SIGLOS XVIII y XIX
}

\author{
SALVADOR ALMENAK \\ Universidad de Valencia
}

El propósito de estas notas es ofrecer una descripción escueta de la literatura dedicada al pensamiento económico en España, publicada desde las I Jornadas (Madrid, febrero 1974), para que - siguiendo las indicaciones de los organizadores de estas III Jornadas- pueda servir de marco, referencia 0 acicate en el debate subsiguiente a las comunicaciones. Es una descripción improvisada e incompleta, que espero mejorar con la ayuda de los asistentes. Concluiré la relación con unas reflexiones generales que me ha sugerido el análisis de dicha literatura.

Hace años el profesor D. Iparraguirre (1975) - hoy ya desaparecidoestablecía un balance historiográfico sobre el pensamiento económico en España en el siglo xvıı con referencias al libro de Sarrailh (1954), obras de carácter general de A. Domínguez Ortiz, F. Díaz Plaja, V. Palacio Atard, R. Herr, así como el libro de G. Anes (1969). Destacaba, por su carácter monográfico, el volumen de M. Bitar (1968). Añadía una referencia a un artículo de Muñoz Perea, tres de R. S. Smith, uno de F. Venturi (1962), al libro $\mathrm{H}$. Berindoague Le mercantilisme en Espagne (1929), y al volumen colectivo sobre las Sociedades Económicas de 1972.

Para el siglo xix menciona el catálogo elaborado por Roglá de Leuw (1974), las visiones panorámicas establecidas por M. von Heckel (1890), y G. Franco (1923), un antiguo estudio de Olascoaga de 1896, unos artículos de G. Prieto, y las referencias al libro de E. Lluch (1973) sobre el pensamiento económico en Cataluña, al breve estudio de Martínez-Barbeito de 1963 sobre economistas gallegos, al prefacio de J. M. Zumalacárregui sobre economía matemática en España, y al estudio de R. Calle sobre la literatura financiera.

Con respecto a este punto de partida, puede afirmarse que en la década 
de los setenta se consolida una literatura especializada, a la que no son ajenos dos factores característicos: la formación de grupos de investigación, y la coordinación de esfuerzos en la comunicación científica (como la realización de las I Jornadas, la publicación de la colección de «Clásicos del pensamien. to económico español» o de números monográficos en «Información Comercial Española», «Hacienda Pública Española», etc.).

Las investigaciones sobre el pensamiento económico en España durante el siglo xvin se enmarcan, en los últimos quince años, dentro de un debate de revisión sobre la «llustración», sus etapas y las relaciones entre pensamiento ilustrado y pensamiento liberal (por ej.: G. Anes, 1969; Elorza, 1970; y su revisión en Elorza, 1978; Mestre, 1976; Abellan, 1981; Venturi, 1984; Alberola y La Parra, edts., 1986).

De todos modos, no se posee en la actualidad un hilo conductor de referencia semejante al que para el período anterior debemos a $\mathrm{M}$. Grice-Hutchison (1978). Las dos únicas síntesis disponibles se deben a R. S. Smith (1971) para el mercantilismo, y - con mayor extensión y alcance- al profesor F. Estapé (1982). Una interpretación cercana a la idea de progreso constante hacia el liberalismo, en R. Anes (1986), y la interpretación del proceso como conflicto entre «tradición y novedad» [G. Anes, $1987 \mathrm{~b}$ ].

Una de las principales novedades del desarrollo historiográfico ha sido la presentación de estudios sobre el pensamiento económico desde una perspectiva regional, en muchos casos abarcando también la primera mitad del siglo xix. Además del libro de E. Lluch (1973 y 1976) sobre Cataluña [Romá, Capmany, Caresmar, Amat, Dou, Gassó, Oliver, Jaumeandréu]; F. Dopico (1976 y 1978) para Galicia [Martín Sarmiento, De Castro, Cornide, Somoza, Sánchez, Labrada]; Freije (1982) y Barrenechea $(1985 c)$ para el País Vasco [Uztariz, Uría, Arriquívar, Foronda]; Martínez Cachero (1976) para Asturias [Campillo, Campomanes, Jovellanos, Flórez Estrada, Canga Argüelles, Mon]; Lluch (1974 y 1980) y Lluch y Almenar (1983) para el País Valenciano. Los estudios de Lluch replantean la naturaleza y heterogeneidad del pensamiento económico ilustrado en España.

Se ha avanzado en el estudio vertical o temático: sobre los economistas y las colonias, además del ya citado Bitar (1968), Llombart (1979), y P. Schwartz (1983); sobre las teorías y políticas respecto a la población [Callahan, 1978, y sobre todo el libro monográfico de M. Martín, 1984]; y sobre las propuestas de análisis y reforma de la Hacienda pública: los estudios de Calle (1978) y Lasarte (dir.) (1980), y -para el contraste entre proyectos y realidad-Fontana (1973, cap. I) y Artola (1982).

Especial atención han merecido las Sociedades Económicas de Amigos del País. Su vinculación con las Sociedades de Agricultura [Llombart, 1976 b], y el conflicto con los intereses comerciales [Llombart, 1981], la defensa del 
agrarismo en la de Murcia [López Casares, 1975]. Además del repertorio de los Demerson y Aguilar Piñal (1974), los estudios específicos sobre la Aragonesa [Forniés, 1978], Valladolid [Enciso, 1975], Tenerife [Romeu, 1979], y los referidos a Santiago de Compostela [C. Fernández Casanova], Las Palmas [C. García del Rosario], La Mancha [Barreda Fontes], que no he podido consultar.

Al estudio de la influencia del pensamiento económico exterior, unas veces centrado en bibliografías de traducciones [Reeder, 1973 y 1978], y otras en estudios monográficos: sobre Jovellanos [Polt, $1964 t$ ], la recepción de Raynal [García Regueiro, 1979], la peculiar introducción de Cantillon por Danvila [Estapé, 1971; Lanzuela, 1976], sobre las dificultades para la penetración de Adam Smith [Lasarte, 1976], y sobre la influencia de los Fisiócratas en España y sus relaciones con la agronomía [Lluch y Argemi, 1985, aunque se trata de un estudio más amplio].

En relación con la difusión no existen monografías sobre control editorial o de lectores, pero hay que mencionar el estudio sobre el «Seminario de Agricultura" [Díaz Rodríguez, 1980].

Los trabajos dedicados a un autor o un grupo reducido son los más abun- . dantes. Sobre Uztáriz [Freije, 1982, vol. I; Fernández Durán, 1976, y su reciente Tesis doctoral]; sobre Campillo [Tiryakian, 1978]; la reedición de Macanaz (1972); sobre Ward [Castellano, 1982]. Sobre Campomanes se han concentrado varios investigadores [Reeder, 1975; Tomás y Valiente, 1975; Llombart, $1976 a, 1976 b$ y 1979; Rodríguez, 1976]. Sobre Arriquívar [Astigarraga, 1986]; sobre Foronda [Barrenechea, $1985 a, 1985 b$ y 1986; Benavides y Rollán, 1984]; sobre Cabarrús [García Regueiro, 1985]; sobre el magistrado Bruna y Ahumada [G. Anes, $1987 a$ ]; los proyectos fiscales de Floridablanca [G. Anes, 1974]; el Marqués de Santa Cruz [Galmes de Fuentes, 1984]; Alonso Ortiz [Fernández Marugán y Schwartz, 1978]; Sempere y Guarinos [López Estornell, 1978]; Ramón Campos [Guy, 1980]. Los casos de Normante [Forniés, 1976; Peiró, 1984], y Ramón de Salas [Mateo del Peral, 1978], están unidos a las primeras cátedras de economía.

\section{III}

En comparación con la literatura sobre el pensamiento económico del Siglo de las Luces, la que versa sobre el xix es mucho menos abundante. Como ejes conductores sólo cabe citar, de nuevo, el estudio de F. Estapé (1982) y los muy anteriores de Heckel (1890) y Franco (1923), reeditados en estos años.

La recepción del pensamiento económico exterior ha merecido mayor 
atención. A partir de diferentes estudios de R. S. Smith se han ordenado las traducciones [Cabrillo, 1978]; la introducción de Malthus [Llombart, 1973], de Sismondi [Bru, 1980], de J. Bentham [Schwartz, 1976; Schwartz y Rodríguez Braun, 1983], los economistas ricardianos [Cabrillo, 1977; Almenar, 1980], la escuela optimista francesa [Lluch, 1970], de Cobden [Almenar y Velasco, 1987]. La influencia del primer pensamiento socialista [Maluquer, 1977]. Sobre la influencia de Marx [Gasch, 1975 y 1983; Ribas, 1981 y 1984; Velarde, 1983]; y sobre el «socialismo de cátedra» [Velarde, 1986].

La función difusora desempeñada por la enseñanza de la economía política todavía permanece diseminada en estudios muy particulares [Alegret y Lluch, 1974; Blanco Canales, 1976; Beltrán, 1981 y 1985; Almenar, $1982 \mathrm{~ms}$ ]. En cambio existe una monografía sobre los estudios de estadística de los principales economistas [Sánchez Lafuente, 1975].

Existen, igualmente, tratamientos sectoriales o temáticos, gran parte de los mismos analizan el proceso policy-making. Sobre análisis o proyectos respecto a la Hacienda [Estapé, 1971 b; Fontana, 1971, 1972, 1973, 1976 y 1977; Fontana y Garrabou, 1986; Lasarte, 1976; Calle, 1978; Mateo del Peral, 1979]; la polémica entre librecambio y proteccionismo y la política arancelaria [Schwartz, 1970; Lluch, 1973 y 1976; Martín Niño, 1978; Nadal Farreras, 1978; Costas, 1982; Alvarez, 1985; Serrano Sanz, 1987; Fradera, 1987; Varela, 1977]; la política monetaria [Ródenas, 1978; Martín Aceña, 1981)].

Los enfoques relativos a un ámbito regional se reducen a los trabajos, ya citados, de Lluch, Dopico y Martínez Cachero, añadiendo -para Cataluna- [Artal, 1972 y 1984]. Y los estudios monográficos o parciales sobre un autor son también, comparativamente, escasos. Sobre Flórez Estrada [Almenar, $1976 a$ a $1976 b$ y 1980], sobre M. M. Gutiérrez [Grice-Hutchison], sobre A. Borrego [C. de Castro, 1975], sobre Figuerola [Cabrillo, 1981; Costas, 1983 y 1984]. Sobre la polifacética obra de Joaquín Costa [Maurice y Serrano, 1977; Cheyne, 1981; Serrano, 1983].

\section{IV}

La literatura descrita manifiesta al mismo tiempo un importante crecimiento cuantitativo y una marcada heterogeneidad en los énfasis y en las orientaciones. También revela la existencia de importantes lagunas en el conocimiento primario del pensamiento económico en España, en especial del siglo XIX.

La historografía más reciente denota una mayor especialización, la utilización de nuevos procedimientos, la búsqueda de un estatus analítico propio 
$y$, en particular, el esfuerzo por definir un esquema explicativo de los procesos de comunicación $y$ adaptación transnacional e intertemporal del pensamiento económico [Lluch, 1980]. Esta reflexión ha “teñido» con cuatro rasgos, al menos, la literatura de las dos últimas décadas:

1) Al constatar la necesidad de una mayor precisión en las relaciones entre análisis, política económica e ideología, se han abandonado o redefinido progresivamente categorías genéricas y equívocas («ilustración», «mercantilismo», «liberalismo», etc.).

2) La atención por las fuentes y por la influencia del pensamiento económico exterior ha supuesto la práctica desaparición de lo que Einaudi calificó como «precursorismo».

3) El esquema "absolutista" atenuado, por ejemplo Becker-Stigler [Stigler, 1982 ], encuentra serias dificultades para explicar la aceptación de teorías en países receptores y no innovadores y que no poseen abundante capitalconocimiento, en los cuales la información es incompleta, la obsolescencia de las teorías es muy lenta, y el riesgo de la elección es reducido. La constatación de estas dificultades ha conducido a planteamientos generalmente «externalistas» o moderadamente «relativistas». El problema por excelencia es, entonces, el análisis de la «adaptación» o «aclimatación» del pensamiento económico exterior.

4) A su vez, la percepción de marcos culturales o sociales diferenciados de reflexión y elaboración del pensamiento económico ha supuesto un estímulo para la investigación biográfica y los estudios de ámbito regional.

\section{V}

Además de la existencia de zonas oscuras o desconocidas en el pensamiento económico de los siglos xvirr y xix, existe un elemento adicional por el que se podría calificar de insatisfactorio el estado de la historiografía, aun constatando el avance ya señalado. Creo que podemos compartir la opinión que es deseable progresar en una mayor precisión en la investigación de las relaciones entre teoría y política económica de modo que puedan facilitarse las síntesis y las comparaciones o, al menos, los contrastes, todos ellos bastante infrecuentes hasta el momento.

Voy a proponer a discusión un marco de aproximación instrumental y sencillo. En su formulación más simple una teoría está compuesta de diversos conceptos o submodelos cuyo sentido depende de la función que internamente desempeñan. Gran parte de la historiografía que nos ocupa, para expresarlo de un modo impersonal, se enfrenta al problema de caracterizar unos modelos 
de pensamiento económico, en gran medida formados por elementos «importados» y provenientes de teorías diversas, en el tiempo y el espacio. Por tanto, el primer problema del análisis se refiere a la detección de los cambios de sentido o de función interna de cualquier concepto o submodelo, al pasar de la teoría original a la receptora. El siguiente problema es el análisis de la coherencia teórica. Y el tercero, la relación entre los submodelos teóricos y la política económica que suele deducirse unilateralmente de ellos. Es en este punto donde convendría especificar seis áreas que - de ser tenidas en cuenta- facilitarían las comparaciones y las posibles síntesis posteriores a los trabajos monográficos: definición de los derechos de los agentes sociales (propiedad, control); producción (rendimientos) y población; relación de producción y demanda (precios, dirección de causalidad, comercio exterior); relaciones entre la(s) agricultura(s) y las manufacturas (precios y rentas); dinero, interés y precios; efectos directos e indirectos del sistema fiscal, y de las regulaciones.

Tal vez se considere que las escuetas referencias historiográficas y estos comentarios finales son parciales e incompletos. En parte, es cierto. Espero que sean suficientes para iniciar el debate.

\section{REFERENCIAS}

Abellán, J. L. (1981): Historia crítica del pensamiento español, vol. III, Madrid (EspasaCalpe).

Alberola, A., y La Parra, E. (eds.) (1986): La Ilustración Española, Actas del Coloquio Internacional celebrado en Alicante, 1-4 octubre 1985, Alicante (Instituto Juan Gil. Albert).

Alegret, J., y Lluch, E. (1974): “La Economía política". Poema didáctico de B. C. Aribau», Hacienda Pública Española, núm. 27, pp. 187-199.

At.menar, S. (1976 a): «Alvaro Flórez Estrada y la tributación. Economía ricardiana y reforma fiscal en España en el segundo tercio del siglo XIX», Hacienda Pública Española, núm. 36, pp. 21-33.

- (1976 b): "Agrarismo y librecambio en la crisis del Antiguo Régimen. El primer modelo de crecimiento de Alvaro Flórez Estrada», Información Comercial Española, núm. 517 , pp. $58-81$.

- (1980): «El pensamiento económico de A. Flórez Estrada. Economía ricardiana y reformismo radical», en A. Flórez Estrada (1980), pp. XXXV-CXXIII.

- (1982 ms): Notas improvisadas sobre las primeras cátedras de economía en España (1780-1842), ms. 9 pp. (Informe para el proyecto aThe Institutionalisation of Political Economy in Europe», Cambridge y Florencia).

Al.menar, S., y Velasco, R. (1987): "Una etapa en la consolidación del librecambio en España: el viaje de Richard Cobden por Andalucía», en G. Ruiz (coord.) (1987), pp. 105.118.

Alvarez, L. (1985): La politica comercial española 1849-1891, tesis de licenciatura (Universidad de Valencia, Fac. de CC. Económicas y Empresariales). 
Anes, G. (1969): Economia e Ilustración en la España del siglo XVIII, Esplugues de Llobregat, Barcelona (Ed. Ariel).

- (1974): «La Contribución de frutos civiles entre los proyectos de Reforma Tributaria en la España del siglo xvıI»», Hacienda Pública Española, núm. 27, pp. 21-30+31-45.

- (1987 a): «Pensamiento ilustrado sobre problemas agrarios en Andalucía: la aportación de Francisco de Bruna y Ahumada», en Ruiz (coord.) (1987), pp. 85-104.

- (1987 b): "Tradición y novedad de las actitudes ilustradas", Cuenta y Razón, núm. 29. pp. 25.38 .

- (1986): «Hacia la configuración del pensamiento liberal», en Popescu et al. (1986). pp. 99-116.

Anes, G.; Rojo, L. A., y Tedoe, P. (eds.) (1983): Historia ecunómica y pensamiento sucial. Estudios en homenaje a Diego Mateo del Peral, Madrid (Alianza Ed./Banco de España).

ANEs, R. (1988): "Ideas económicas de los ilustrados asturianos», Revista de Occidente, núm. 82, marzo, pp. 58.73.

Argemí, Ll. (1984): «Llibertat mitigada per a l'agricultura», L'Avenç, núm. 67, pp. 40-44.

ArTAL, F. (1972): «Vers una política econòmica nacionalista burgesa (1840-1913)», en VV. AA., Economia crítica: una perspectiva catalana, Barcelona (Edicions 62), pp. 269. 298.

- (1984): «Nació $i$ poder en el pensament econòmic catalá (1840-1939)", L'Aveņ̧, núm. 67, pp. 50.55.

Artola, M. (1982): La Hacienda del Antiguo Régimen, Madrid (Alianza Ed./Banco de España).

Astigarraga Goenaga, J. (1986): «El pensamiento económico de Nicolás de Arriquívar», en Popescu et al. (1986), pp. 67-82.

BARREnechea, J. M. (1985a): Valentín de Foronda, reformador y economista ilustrado, Prólogo de E. Lluch (Cartas sobre Valentín de Foronda), Vitoria (Diputación Foral de Alava, Dpto. de Publicaciones).

- (1985 b): "Valentín de Foronda ante la fisiocracia», en Lluch y Argemí (1985), cap. V, pp. 153-183.

- (1985c): «Economistas vascos del siglo xvirl: Uztáriz, Uría Nafarrondo, Arriquíbar y Foronda», en M. A. Larrea et al. (1985), pp. 193-224,

- (1986): «El pensamiento económico de Valentín de Foronda (1751-1821)», en Popescu et al. (1986), pp. 83-97.

Beltrán, L. (1981): «El estudio de la Economía en Españan, Moneda y Crédito, núm. 157, pp. 3-18.

- (1985): «La creación de cátedras de economía en España», Moneda y Crédito, núm. 173, pp. $47-50$.

Benavides, M., y Rollán, C. (1984): «Introducción» a Foronda (1984), pp. 11-313.

Bitar Letaif, M. (1968): Economistas españoles del siglo XVIII: Sus ideas sobre la libertad de comercio con Indias, Prólogo de J. A. Maravall, Madrid (Ed. Cultura Hispánica).

Blanco Canales, R. (1976): «La enseñanza de la Economía en España en la primera mitad del siglo xix», Revista de Economía Política, núm. 74, pp. 77.94.

Bru, S. (1980): "La difusió a Espanya de les idees econòmiques de Sismondi», Recerques, núm. $10, \mathrm{pp} .33-50$.

Cabarrús, F. de (1973): Cartas sobre los obstáculos que la naturaleza, la opinión y las leyes oponen a la felicidad pública (1795), Estudio preliminar por J. A. Maravall, Madrid (M. Castellote Ed.).

Cabrillo, F. (1977): «Una controvertida traducción al español de los "Principios de Economía Política y Tributación" de David Ricardon, Moneda y Crédito, núm. 143, pp. 187-191.

- (1978): "Traducciones al español de libros de economía política (1800-1880)», Moneda y Crédito, núm. 147, pp. 71-103.

- (1981): «El programa de Economía política de D. Laureano Figuerola», Moneda y Crédito, núm. 162 , pp. $49-59$. 
Callahan, W. J. (1978): “Caridad, sociedad y economía en el siglo xviru, Moneda y Crédito, núm. 146, pp. 65-77.

Calle SAIZ, R. (1978): La Hacienda Pública en España. Un análisis de la literatura financiera, Prólogo de L. Beltrán, Madrid (Servicio de Publicaciones Fundación Universitaria San Pablo-CEU).

Campomanes, P. R. (1975a): Discurso sobre el fomento de la industria popular (1774), Discurso sobre la educación popular de los artesanos y su fomento (1775), edición y Estudio preliminar por J. Reeder, Madrid (Instituto de Estudios Fiscales).

- $(1975$ b): Tratado de la Regalia de Amortización, Estudio preliminar de F. Tomás y Valiente, Madrid (Ed. Revista de Trabajo).

Castellano, J. L. (1982): «Estudio preliminar», en Ward (1982), pp. VII-LXV.

Castro, C. de (1975): Romanticismo, periodismo y politica: Andrés Borrego, Madrid (Tecnos).

Cheyne, J. G. (1981): Estudio bibliográfico de la obra de Joaquín Costa (1846-1911), Zaragoza (Guara Ed.).

Costa, J. (1983): Colectivismo agrario en España, Introducción y edición por C. Serrano, Zaragoza (Guara Ed./Instituto de Estudios Agrarios, Pesqueros y Alimentarios), 2 vols.

Costas, A. (1982): Politica económica y reforma liberal (1868-1874) (Un esquema inter. pretativo de! porqué y cómo lue posible la reforma económica de 1868), tesis doctoral, Universidad de Barcelona.

- (1983): «El viraje del pensamiento político-económico español a mediados del siglo xIX: la "conversión" de Laureano Figuerola y la formulación del librecambismo industrialista», Moneda y Crédito, núm. 167, pp. 47-70.

- (1984): «Laureá Figuerola, Catalunya i la reforma lliberal», L'Avenç, núm. 67, pp. 46-49.

- (1988): Apogeo del liberalismo en la "Gloriosa». La reforma económica en el Sexenio liberal (1868-1874), Madrid (Siglo XXI de España Ed.).

Deforneaux, M. (1965): Pablo de Olavide, el afrancesado, México (Renacimiento).

Díaz Rodríguez, F. (1980): Prensa agraria en la España de la Ilustración. El eSemanario de Agricultura y Artes dirigido a los Párrocos» (1797-1808), Madrid (Servicio de Publicaciones Agrarias, Ministerio Agricultura).

Domergue, L. (1971): Jovellanos à la Société Economique des Amis du Pays de Madrid (1778-1795) (France-Ibérie Recherche).

Dopico, F. (1976): «Pensamiento económico y crisis del Antiguo Régimen en Galicia», Información Comercial Española, núm. 512, pp. 119-125.

- (1978): A Ilustración e a Sociedade Galega. A visión de Galicia dos economistas ilus. trados, Prólogo de X. García-Lombardero, Vigo (Ed. Galaxia).

Elorza, A. (1970): La ideologia liberal en la Ilustración española, Madrid (Ed. Tecnos).

- (1975): El fourierismo en España, Madrid.

- (1978): «Las ideas políticas: Ilustración y anti-Ilustración», Historia 16, Extra VIII, diciembre, pp. 69.86.

EstaPÉ, F. (1971 a): Ensayos sobre bistoria del pensamiento económico, Esplugues de Llobregat, Barcelona (Ed. Ariel).

- (1971 b): La reforma tributaria de 1845 . Estudio preliminar y consideración de sus precedentes inmedialos, Madrid (Instituto de Estudios Fiscales).

- (ed.) (1973): Textos olvidados, Madrid (Instituto de Estudios Fiscales).

- (1982): «Pensamiento económico», en Economía Planeta. Diccionario Enciclopédico, tomo 7 , pp. 283.405 .

FERnÁNDEZ DuRÁN, R. (1976): “Gerónimo de Uztáriz. Las fuentes de su pensamiento económicon, Información Comercial Española, núm. 512, pp. $75 \cdot 100+101-107$.

- (1988): "Gerónimo de Uztáriz (1670-1732). Vida de un "funcionario" en la Corte de Felipe V», Información Comercial Española, núm. 656, abril, pp. 29.41.

Fernández Marugán, F., y Schwartz, P. (1978): «El Ensayo de José Alonso Ortiz. Monetarismo smithiano en la España de los Vales Reales», en Otazu (ed.) (1978), pp. 393. 435.

Flórez Estrada, A. (1980): Curso de economia politica (1828), Introducción por E. Lluch, Estudio preliminar y edición de S. Almenar, Madrid (Instituto de Estudios Fiscales). 
Fornies Casals, J. F. (1976): «La cátedra de Economía Civil y Comercio de Zaragoza en el período de la Ilustración (1784-1808)», Información Cumercial Española, núm. 512, pp. $108-118$.

Foronda, V. de (1984): Los Sueños de la Razón, edición e Introducción de M. Benavides y C. Rollán, Madrid (Ed. Nacional).

Fontana, J. (1971): La quiebra de la monarquia absolula (1814-1820), Barcelona (Ariel).

- (1972): «La supervivencia del mito de la Unica contribución. Noticia de algunos arbitristas españoles de comienzos del siglo X1X», Hacienda Pública Española, núm. 17, pp. 111-119.

- (1973): Hacienda y Estado en la crisis final del Antiguo Régimen español: 1823-1833. Madrid (Instituto de Estudios Fiscales).

- (1976): «José López Juana Pinilla, una gran figura de la Hacienda española del siglo xix», Hacienda Pública Española, núm. 36, pp. 93-100.

- (1977): La Revolución Liberal (Politica y Hacienda 1833-1845), Madrid (Instituto de Estudios Fiscales).

Fontana, J., y Garrabou, R. (1986): Guerra y Hacienda. La Hacienda del gobierno central en los años de la Guerra de la Independencia (1808-1814), Alicante (Instituto Juan Gil-Albert, Diputación de Alicante).

Fradera, J. M. (1987): Indústria i mercat. Les bases comercials de la indústria cataluna moderna (1814-1845), Barcelona (Ed. Crítica).

Freije, A. (1982): Modelos vascos de desarrollo en el siglo XVIII. 1. Uztáriz. 2. Arriquí bar y Foronda, 2 vols., San Sebastián (Haramburu Ed.).

Franco, G. (1923): «La teoría económica de nuestro tiempo. España», Anales de Economía, 3. 'ं época, núm. 15, 1972, pp. 5-28.

Galmes de Fuentes, A. (1984): «El Marqués de Santa Cruz de Marcenado y su "Rapsodia Económica"», en Santa Cruz (1984), pp. XI-XLIX.

García Delgado, J. L. (ed.) (1976): La cuestión agraria en la España contemporánea, Madrid (Ed. Cuadernos para el Diálogo).

García Regueiro, O. (1979): «Intereses estamentales y pensamiento económico: la versión española de la "Historia" de Raynal», Moneda y Crédito, núm. 149, pp. 85-118.

- (1985): «El pensamiento económico de Francisco de Cabarrús: dos escritos inéditos», en Iglesias (comp.) (1985), vol. II, pp. 151-171.

GASCH, E. (1975): «Difusió del "Manifest Comunista" a Catalunya i Espanya (1872-1939)», Recerques, núm. 5, pp. 21-30.

- (1983): Marx a Espanya. Un estudi sobre la difusió de l'obra de Marx (1869-1939), L'Hospitalet de Llobregat, Barcelona (ICE/Univ. Autónoma de Barcelona).

Gil Novales, A. (comp.) (1979): Homenaje a Nóel Salomon. Ilustración española e independencia de América, Barcelona (Univ. Autónoma de Barcelona).

GonzÁLEZ, M. J. (1988): «Campomanes y Jovellanos ante el marco institucional de la economía de mercado», Información Comercial Española, núm. 656, abril, pp. 103-113.

Gooowin, C. D. W., y Holley, I. B., Jr. (eds.) (1968): The Transfer of Ideas: Historical Essays, Durham, N. C. (The South Atlantic Quarterly).

Grice-Hutch ison, M. (1978): El pensamiento económico en España (1117-1740) («Early Economic Thought in Spain 1117-1740», Londres), Barcelona (Ed. Crítica), 1982.

Guy, A. (1980): «Ramon Campos, disciple de Condillac», en Pensée bispanique et philosopbie des lumières, Toulouse (Pubs. Université).

HerR, R. (1958): España y la revolución del siglo XVIII, Madrid (Ed. Aguilar), 1964.

Iglesias, M. C., et al. (comp.) (1985): Homenaje a José Antonio Maravall, Madrid (Centro de Investigaciones Sociológicas), 3 vols.

Iparragurrre, D. (1975): “Historiografía del pensamiento económico español», Anales de Economia, 3.' época, núms. 25-26, pp. 5.38.

Jovellanos, G. M. de (1984-): Obras completas. I. Obras literarias, Prólogo de J. M. Caso González, Oviedo (Centro de Estudios del Siglo XVIII/Ilmo. Ayuntamiento de Gijón).

Lanzuela, S. (1976): «Notas sobre la peculiar introducción del pensamiento económico de Cantillon por un ilustrado valenciano: B. J. Danvila y Villarrasam, en I Congreso 
de Historia del Pais Valenciano, abril 1971, Valencia (Universidad de Valencia), vol. III, pp. 641-650.

Larrea, M. A., et al. (1985): Historia del País Vasco (Siglo XVIII), Bilbao (Universidad de Deusto).

Lasarte, I. (1976): Economia y Hacienda al final del Antiguo Régimen. Dos estudios ( «Adam Smith ante la Inquisición y la Academia de la Historia», "La consulta al país de 1809: un alegato contra la Hacienda del Antiguo Régimen»), Madrid (Instituto de Estudios Fiscales).

Lasarte, I. (dir.); Castellano, J. L., y Arias de Sanuedra, I. (1980): La Hacienda en la bibliografia de 1700 a 1845. Vol. I: Siglo XVIII, Madrid (Instituto de Estudios Fiscales).

López Casares, G. (1975): «La Sociedad Económica de Amigos del País de Murcia (1777. 1808 )», Anales de Economia, 3.` época, núms. 25-26, pp. 39.63.

López Estornele, M. (1978): «Pensamiento económico ilustrado en el País Valenciano: una aportación a la bibliografía de Sempere y Guarinos», Investigaciones Económicas, núm. 6, pp. 213-222.

Llombart, V. (1973): «Anotaciones a la introducción del “Ensayo sobre la población”. de Malthus, en España», Moneda y Crédito, núm. 126, pp. 79-86.

- (1976a): «A propósito de los intentos de reforma de la Hacienda castellana en el si. glo xviII: Campomanes frente al proyecto de Unica Contribución», Hacienda Pública Española, núm. 38, pp. 123.132.

- $(1976 b)$ : "Ley Agraria" y "Sociedades de Agricultura". La idea inicial de Campomanes», Información Comercial Española, núm. 512, pp. 57-67+68-74.

- (1979): "Mercantilismo tardío, "liberalización" comercial y explotación colonial americana: las "Reflexiones sobre el comercio español a Indias" (1762) del Conde de Campomanes", en Gil Novales (comp.) (1979), pp. 333-343.

- (1981): «El sorgiment de les Societats Econòmiques i llur conflicte amb les institucions comercials», Recerques, núm. 11, pp. 181-198.

LluCH, E. (1970): «Esquema de evolución del pensamiento económico en España en la segunda mitad del siglo xIX», en El pensamiento económico en Cataluña entre el renacimicnto económico y la revolución industrial, tesis doctoral, Univ. de Barcelona, vol. II, pp. 445-453.

- (1973): El pensament econòmic a Catalunya (1760-1840). Els orígens ideològics del proteccionisme $i$ la pressa de consciència de la burgesia catalana, Barcelona (Edicions 62).

- (1974): "Pensamiento económico e industrialización sedera valenciana (1740-1840)», en VV. AA., Siete estudios sobre historia contemporánea del País Valenciano, Valencia (Fac. de Filosofía y Letras), pp. 57.94.

- (1976): «La Cataluña industrial: del mercantilismo al prohibicionismo», Información Comercial Española, núm. 517, pp. 27-35.

- (1980): "La "Idea general de la policía" de Tomás Valeriola», Recerques, núm. 10, pp. $125-137$.

Lluch, E., y Argemí, Ll. (1982): «La fisiocràcia a Espanya», Recerques, núm. 12, pp. 7.37

- (1985): Agronomía y Fisiocracia en España (1750-1820), Prólogo y Epílogo por F. Es. tapé, Valencia (Institució Alfons el Magnànim/IVEI).

Lluch, E., y Almenar, S. (1983): «El pensamiento económico en el País Valenciano», en Història de l'economia valenciana, Valencia (Generalitat Valenciana y Diputació Provincial de València), pp. 301-306.

Macanaz, M. de (1972): Testamento politico. Pedimiento fiscal, Noticia biográfica por J. Maldonado Macanaz, edición y notas por F. Maldonado de Guevara, Madrid (Ed. Instituto de Estudios Politicos).

Maluquer de Motes, J. (1977): El socialismo en España 1833-1868, Barcelona, Ed. Crítica.

Martín ACEÑ A, P. (1981): «España y el patrón oro 1880-1913», Hacienda Pública Española, núm. 69, pp. 267-290.

Martín Niño, J. (1978): "La discusión en el Congreso de los Diputados de la Ley de Reforma Arancelaria de 1849. Unas notas», Hacienda Pública Española, núm. 55, pp. 251-274. 
Martín Rodrigues, M. (1984): Pensumicnto conómico español sobre la publación. De Solo a Malanegui, Madrid (Ed. Pirámide).

Martínez Cachero, L. A. (1976): Economistas y bacendistas asturianos (Aportaciones para la bistoria económica de Asturias), Salinas, Asturias (Ayalga Ed.).

Martínez Chacón, E. (ed.) (1985): Electos perniciosos del lujo: las Carlas de D. Manuel Romero del Alamo al "Memorial Lilerario» de Madrid (1789), Prólogo de J. L. García Delgado, Oviedo (Universidad de Oviedo).

Mateo del. Peral, D. (1976): «Los antecedentes de la abolición del diezmo (EI debate en las Cortes del Trienio Liberal)m, en García Delgado (ed.) (1976), pp. 289-310.

- (1978): «Sobre Ramón de Salas y la incorporación de la "Economía civil" a la enseñanza universitaria», Investigaciones Económicas, núm. 6, pp. 167-190.

Mestre, A. (1976): Despotismo e Ilustración en España, Esplugues de Llobregat, Barcelona (Ariel).

Maurice, J., y Serrano, C. (1977): J. Cosia: crisis de la Restauración y populismo (1875. 1911), Madrid (Siglo XXI Ed.).

Molas Ribalta, P. (1985): La burguesia mercantil en la España del Antiguo Régimen, Madrid (Ed. Cátedra).

Nadal Farreras, J. (1978): Comercio exterior con Gran Bretaña (1777.1914), Madrid (Instituto de Estudios Fiscales).

Normante y Carcavilla, L. (1984): Discurso sobre la utilidad de los conocimientos económico-politicos, y la necesidud de su estudio metódico. Proposiciones de Economia Civil y Comercio. Espiritu del Señor Melón en su Ensayo politico sobre el Comercio, edición e Introducción de A. Peiró Arroyo, Zaragoza (Diputación General de Aragón).

Otazu, A. (1978): Dinero y crédito (siglos XVI al XIX). Actas del I Coloquio Internacional de Historia Económica, Madrid.

Peiró Arrovo, A. (1984): «Burguesía, Ilustración y análisis económico: Lorenzo Normante y la Cátedra de Economía Civil y Comercio», en Normante (1984), pp. 11-32.

Perdices Blas, L. (1988): "Pablo de Olavide. Apuntes sobre su vida y sus escritos», Información Comercial Española, núm. 656, abril, pp. 43-52.

Polt, J. H. E. (1964): «El pensamiento económico de Jovellanos y sus fuentes inglesas», Información Comercial Española, núm. 512, 1976, pp. 23.56.

Popescu, O., et al. (1986): Aportaciones del Pensamiento Económico Iberoamericano, siglos XVI-XX, Introducción de J. Velarde, Madrid (Ed. de Cultura Hispánica, ICI).

Prados Arrarte, J. (1982): Don Alvaro Flórez Estruda, un español excepcional (17661853) (Discurso de recepción), Madrid (Real Academia Española).

ReEder, J. (1973): «Bibliografía de traducciones, al castellano y catalán, durante el siglo xvili, de obras de pensamiento económicom, Moneda y Crédilo, núm. 126, pp. 57.77.

- (1975): «Estudio preliminar», en Campomanes (1975 o), pp. 11-37.

- (1978): «Economía e Ilustración en España: Traducciones y traductores, 1717-1800», Moneda y Crédito, núm. 147, pp. 47-70.

Rıвas, P. (1981): La introducción del marxismo en España (1864-1939), Madrid (Ed. de la Torre).

- (1984): «Análisis de la difusión de Marx en España», Anthropos, núms. 33-34, pp. 58. 63.

Río Gómez, C. (1984): «Cobden y Bastiat, inspiradores del librecambismo en España», Papeles de Economía Española, núm. 20, pp. 190-191.

Ródenas, C.: (1978): «La política bancaria deflacionista en España a mediados del siglo xix: La influencia de la Ley Peel», Hacienda Pública Española, núm. 55, pp. 351365.

Rodríguez, L. (1975): Reforma e Ilustración en la España del siglo XVIII: Pedro Rodriguez de Campomanes, Madrid (Fundación Universitaria Española).

Rocla dE LEUw, J. (1974): "Catálogo bibliográfico de economía de autores españoles del siglo XIX», Hacienda Pública Española, núm. 27, pp. 253-376, y núm. 28, pp. 227-334.

Ruiz, G. (coord.) (1987): Andalucia en el pensamiento económico, Prólogo de E. Lluch, Málaga (Ed. Arguval). 
Sánchez Blanco, J. (1976): «Bibliografía básica referente a la historia del pensamiento económico en España. Siglos xvı, xviI y xvilı, Información Comercial Española, núm. 512, pp. 126-128.

Sánchez-LAfuente Ferníndez, J. (1975): Historia de la Estadística como ciencia en Es. paña (1500-1900), Madrid (M." Planificación del Desarrollo, Instituto Nacional de Estadistica).

Santa Cruz de Marcenado, Marqués de (A. Navia Osorio) (1984): Rapsodia económico política monárquica (1782), Oviedo (Universidad de Oviedo).

Sarrailh, J. (1954): La España ilustrada de la segunda mitad del siglo XVIII, México (Ed. FCE), 1957.

Schwartz, P. (1970): "De la libertad de comercio" por José Joaquín de Mora. Una defensa del librecambio a mediados del siglo xix», Anales de Economia, núms. 5-8, pp. 187.224 .

- (1976): "La influencia de Jeremias Bentham en España", Información Comercial Es. pañola, núm. 517, pp. 37-67.

- (1983): «Cuatro economistas ante el fenómeno colonial español: Campomanes, Adam Smith, Flórez Estrada y Bentham», en G. Anes et al. (eds.) (1983), pp. 129.158.

Schwartz, P., y Rodrícuez Braun, C. (1983): «Cartas españolas de Jeremías Bentham», Moneda y Crédito, núm. 165, pp. 59-88.

Serrano, C. (1983): "Introducción al "Colectivismo agrario"», en Costa (1983), pp. 9-77.

Serrano Sanz, J. M. (1987): El viraje proteccionista en la Restauración. La politica comercial española, 1875-1895, Prólogo de J. L. García Delgado, Madrid (Siglo XXI de España Ed.).

Sмiтh, R. S. (1968): «English Economic Thought in Spain, 1776-1848», en Goodwin y Holley (eds.) (1968), pp. 106-137.

- (1971): "Spanish Mercantilism: A Hardy Perennial", Soutbern Economic Journal, vol. XXXVIII, julio, pp. 1-11.

Stigler, G. J. (1982): «Nobel Lecture: The Process and Progress of Economics», Journal of Political Economy, núm. 91 (4), pp. 529.545.

Tiryakian, J. C. (1978): «Camplillo's Pragmatic New System: A Mercantile and Utilitarian Approach to Indian Reform in Spanish Colonies of the Eighteenth Century", History of Political Economy, 10: 2, pp. 223.257.

Tuñón de Lara, M., y Botrel, J. F. (eds.) (1974): Movimiento obrero, politica y litera. tura en la España contemporánea, Madrid (Ed. Cuadernos para el Diálogo).

Varela Ortega, J. (1977): Los amigos politicos. Partidos, elecciones y caciquismo en la Restauración (1875-1900), Madrid (Alianza Ed.).

- (1988): Jovellanos, Madrid (Alianza Ed.).

Velarde, J. (1974 a): Introducción a la bistoria del pensamiento económico español en el siglo $X X$, Madrid (Ed. Nacional).

- (1974 b): «Primera aproximación al estudio de la Universidad de Oviedo como enlace entre la Institución Libre de Enseñanza y el Instituto de Reformas Sociales», en Tuñón de Lara y Botrel (eds.) (1974), pp. 223-240.

- (1976): «El nacionalismo económico español y la Institución Libre de Enseñanza. El caso de Leopoldo Alas Argüelles», Información Comercial Española, núm. 517, pp. 96. 101 .

- (1983): «Biblioteca hispana de Marx, Schumpeter y Keynes. Una primera aproximación», Papeles de Economía Española, núm. 17, pp. 374-416.

- (1986): «El socialismo de cátedra en España. Retrato de una polémica», en Popescu et al. (1986), pp. 241-261.

VENTURI, F. (1962): «Economistas y reformadores españoles c italianos del siglo xvinı, en Estapé (ed.) (1973), pp. 201.252.

- (1984): Seltecento riformatore, IV. La caduta dell'Antico Regime (1776-1789). 1. I gran di stati dell'Occidente', Turín (Einaudi).

Ward, B. (1982): Proyeclo Económico (1779), edición y Estudio preliminar de I. L. Castellano, Madrid (Instituto de Estudios Fiscales). 